\title{
A FORMAÇÃO INICIAL DO EDUCADOR DO CAMPO: UM ESTUDO SOBRE A LICENCIATURA EM EDUCAÇÃO DO CAMPO/PROCAMPO
}

\author{
Eliane Miranda COSTA ${ }^{1}$ \\ UFPA/PA \\ elyany2007@hotmail.com
}

Resumo: $O$ estudo analisa o processo formativo da Licenciatura Plena em Educação do Campo (LPEC) em Portel no Marajó. Trata-se de um texto que resulta da pesquisa de mestrado cujo objeto é o Programa de Apoio à Formação Superior em Licenciatura em Educação do Campo. Esta pesquisa adotou como metodologia o estudo de caso de tipo único de abordagem qualitativa tendo como técnicas de coleta $e$ análise de dados: observação não participante, entrevista semiestruturada, questionário fechado e a análise de conteúdo. Para efeito deste textos, as análises e reflexões baseiam-se em trechos de entrevistas e análise de documentos em diálogo com autores como: Arroyo (1999;2004;2012), Caldart (2000;2011), entre outros, que nos permitiram inferir que a LPEC em estudo tem dificuldades, limites de ordem pedagógica e estrutural que, de certo modo, comprometem em parte a qualidade da formação. Contudo, pode-se considerar que esta LPEC representa uma importante ação afirmativa e possibilidade concreta para o acontecer de uma Educação do/no Campo no Marajó.

Palavras-chave: Formação Docente. Licenciatura em Educação do Campo. Educação do Campo.
Abstract: The text analyzes the formative process of the Full Degree in Field Education (LPEC) in Portel in Marajó. It is a text that results from research masters whose object is the Support Programme in Higher Education Degree in Rural Education. This research adopted as a methodology the case study of a unique type of qualitative approach, and how collection techniques and data analysis adopted the non-participant observation, semistructured interviews, closed questionnaire and content analysis. For the purpose of this text, the analyzes and reflections are based on excerpts from interviews and analysis of documents in dialogue with authors such as: Arroyo (1999, 2004, 2012), Caldart (2000; Allowed to infer that the LPEC in study has difficulties, limits educational and structural order that somehow compromises in the quality of training. However, it can be considered that this LPEC represents an important affirmative action is an important and concrete possibility to happen in an Education / Field in the Marajó.

Keywords: Teacher Training. Degree of Field Education. Field Education.

\footnotetext{
${ }^{1}$ Doutoranda do curso de Antropologia (UFPA). Mestre em Educação pela UEPA (2012). Professora titular da Universidade Federal do Pará
} 


\section{Introdução}

Formar educadores/as capazes de contribuir com a construção de uma educação do campo como um paradigma contra hegemônico, isto é, uma educação que contemple a heterogeneidade e a diversidade do campo e, por conseguinte, possibilite configurar outro projeto de campo e de sociedade tem feito da formação docente um dos grandes temas de interesse do Movimento de Educação do Campo, bem como de universidades e intelectuais que, também, têm demonstrado interesse por essa educação. Isso desencadeou a luta pela inserção da referida temática na agenda governamental consubstanciada pela instituição de uma política nacional de formação docente específica para o campo.

A proposta é de uma política pública ancorada em concepções e princípios emancipatórios capazes de ajudar na valorização e no reconhecimento da identidade dos diversos sujeitos que formam a população do campo. Em outros termos, significa dizer uma política que vá além da adaptação e do pseudo reconhecimento. Uma política que respeite e defenda o específico do campo.

Com base nessa reivindicação, em 2006 o MEC aprovou o Programa de Apoio à Formação Superior em Licenciatura em Educação do Campo (Procampo), com o intuito de apoiar a criação do curso de Licenciatura Plena em Educação do Campo (LPEC) em universidades públicas no País. Desde então, esse programa passa a ser a primeira e principal política a tratar da formação do docente o qual atua em escolas do campo. Porém, não atende o que de fato o Movimento requer, tendo em vista tratar-se de um programa, ou seja, uma política emergencial e não uma política permanente.

Ainda assim, pode-se considerá-lo como um importante passo na luta do movimento por conquista de políticas que reconheçam as populações do campo como sujeitos de direitos. Nesse sentido, este texto volta-se para analisar o processo formativo docente na LPEC no Marajó dando ênfase às concepções e princípios defendidos nesse processo. Verifica, também, como a formação do educador do campo se apresenta no contexto das políticas públicas educacionais. 


\section{ASPECTOS BÁSICOS DA FORMAÇÃO: CONCEPÇÃO E PRINCÍPIOS}

Com o apoio de Veiga e Viana (2010, p. 19) parte-se do entendimento de que "não é possível pensar e construir uma proposta formativa sem ter por base a clara concepção de formação e seus princípios fundantes”. Assim, para pensar a formação do educador e educadora do campo adota-se neste estudo a concepção de formação humana, por se compreender a formação como um processo recíproco, de troca, de relações, coadunando assim com o pensamento de Freire (1996, p. 23) quando assegura que "quem forma se forma e re-forma ao formar e quem é formado forma-se e forma ao ser formado".

Diante dessa premissa, entende-se que uma formação docente como formação humana precisa envolver princípios os quais possibilitem o exercício de uma educação libertadora, que possa se realizar com a prática da liberdade e o rompimento das amarras e correntes que historicamente tem aprisionados os povos do campo. Veiga e Viana (2010) defendem que esses princípios devem envolver: a) a prática como ponto de partida e de chegada do processo de formação; b) uma formação voltada para preparar o professor para a atualidade. Isso envolve conhecer os conflitos e contradições que embasam a educação e a sociedade; c) uma formação integrada ao processo de desenvolvimento da escola, reforçando a ideia de Nóvoa (1992) quando enfatiza que a formação não deve se dar alheia ao território de atuação do educador; e d) uma formação desenvolvida em seu contexto histórico.

Os princípios em destaque permitem dizer ser a concepção de formação humana fundamental para se pensar na construção da educação e da escola do campo. A formação humana contrapõe-se à ideia da fragmentação, da dicotomia entre teoria e prática, uma vez que valoriza a prática social coletiva e a formação como ação emancipatória e democrática (VEIGA; VIANA, 2010). Defende-se, desse modo, um processo formativo inicial que possibilite ao educador e educadora do campo intervir e participar criticamente na produção do conhecimento.

A educação da classe trabalhadora do campo precisa ser uma educação que atenda às necessidades dessa classe, em que a formação integral seja o ponto de partida de um projeto 
político pedagógico voltado para a emancipação humana. Para tanto, a escola e o professor precisam exercer papel primordial, com a escola sendo o espaço possível de aquisição e produção dos conhecimentos filosóficos, artísticos, estéticos, técnicos, científicos e tecnológicos produzidos pelos seres humanos ao longo de seu existir; e o professor o mediador desses conhecimentos no diálogo com as práticas sociais para assim contribuir com a construção de uma racionalidade com visões abertas para buscar soluções aos problemas que afligem as populações do campo.

Na perspectiva de Nóvoa (1992, p.18) “a formação do professor é o momento-chave da socialização e da configuração profissional”. Nesse processo, entende-se ser a formação inicial um momento ímpar para o desenvolvimento científico, cultural, social e pedagógico do professor (VEIGA, 2002). Desenvolvimento esse que, no caso do educador do campo precisa estar articulado e sintonizado com as matrizes culturais e as marcas identitárias dos povos do campo.

Nesse sentido, o processo formativo desse profissional precisa se ancorar em uma base teórica e epistemológica sólida a qual não asfixie, mas sim possibilite o professor do campo avançar na relação com o saber. Tal entendimento vai ao encontro do pensamento de Sheibe (2010) quando defende que o professor carece de uma formação sólida e cultural, capaz de ir além do conteúdo pedagógico. Uma formação que supere o ideário de "produto acabado" e se consolide como "um longo e diferenciado processo de desenvolvimento profissional" (GARCIA, 1992, p. 54).

Esse entendimento possibilita afirmar que a formação do educador do campo não pode se dar alheia à realidade da escola do campo em toda sua estrutura, que vai muito além do espaço físico. Trata-se de um território de cidadania e formação humana. De acordo com Caldart (2000, p. 50a) "olhar a escola como um lugar da formação humana significa dar-se conta de que todos os detalhes que compõem o seu dia a dia estão vinculadas a um projeto de ser humano, estão ajudando a humanizar ou desumanizar as pessoas". Para isso, essa autora acredita que os professores precisam assumirem-se como trabalhadores do humanos, pois "quando os professores se assumem como trabalhadores do humano, formadores de sujeitos, muito mais do que apenas professores de conteúdos de alguma disciplina, 
compreendem a importância de discutir" (CALDART, 2000, p. 50a) e, acrescentamos, de ensinar e aprender.

$\mathrm{Na}$ perspectiva dos participantes desse estudo a formação promovida na LPEC via Procampo é pautada em uma concepção a qual busca valorizar os modos de produção da vida das classes trabalhadoras do campo. E isso é feito, por meio de princípios humanizadores que primam pela liberdade e pelo diálogo, como podemos acompanhar nos depoimentos abaixo:

Uma concepção muito forte que costura o Procampo é a concepção crítico social. Essa concepção valoriza os diversos sujeitos, suas experiências, as relações de poder, as estratégias utilizadas em seu cotidiano para garantir sua existência e os seus saberes locais. Quanto aos princípios aposto nos humanizadores. Na valorização da realidade local, das histórias de vida. Princípios filosóficos pelos quais prima o Procampo é a pedagogia para a liberdade, para o aspecto dialógico, como advoga Freire (PF01).

Um dos principais princípios é aproveitar o conhecimento que o aluno tem da comunidade rural, do campo que pertence que é muito variada. Temos, então, uma diversidade, com isso temos um único curso com várias faces por conta dessa enorme diversidade (CP02).

Esses relatos ajudam a evidenciar como princípio dessa formação a escola vinculada à realidade, ao trabalho e à valorização dos diferentes saberes. $\mathrm{O}$ foco no trabalho dá-se no intuito de possibilitar ao educando, como sujeito histórico social, instrumento teórico necessário para posicionar-se de maneira crítica perante as problemáticas do campo, a imposição da ciência moderna, as questões as quais geram tensão na vida no campo. O desafio está em desenvolver atividades a possibilitar o exercício da práxis, no sentido de costurar teoria e prática em um mesmo movimento, conforme expressa Caldart (2011b, p. 104) ao considerar que o desafio da formação do/a educador/a do campo:

É o de construir estratégias pedagógicas que materialize dentro do próprio curso o exercício da práxis, ou seja, que permita o educador aprender a juntar teoria e prática em um mesmo movimento que é o da transformação da realidade (do mundo) e de sua autotransformação humana, de modo que esteja preparado para 
ajudar a desencadear esse mesmo movimento nos processos educativos que participe.

Em linhas gerais pode-se dizer que os princípios defendidos pela LPEC acenam para o desenvolvimento de uma formação pautada na concepção de formação humana, conforme defende-se nesse estudo. E mais, tais princípios contribuem para se reclamar que a formação do educador do campo não pode se dar de qualquer jeito, de qualquer forma, não pode se dar alheia ao movimento de construção do paradigma de educação do campo, que envolve toda a dinâmica de tensão, contradição, conflito.

Trata-se de uma formação que prescinde de elementos ontológicos, epistemológicos, metodológicos e axiológicos na relação com as matrizes históricas e culturais do campo. Daí entender o processo formativo inicial do educador do campo como um momento, uma etapa imprescindível para a construção da identidade sociocultural e da profissionalidade docente no e do campo. Para tanto, depende de uma política que o reconheça como tal, conforme discorre o tópico a seguir.

\section{AS POLÍTICAS EDUCACIONAIS PARA A FORMAÇÃO DO EDUCADOR DO CAMPO}

A formação do educador brasileiro, de acordo com o percurso histórico, ocorre inicialmente no âmbito das Escolas Normais de nível secundário (médio), em cursos específicos voltados para formar professores para o ensino das "primeiras letras" (GATTI; BARRETO; ANDRE, 2011). No campo, parte dessa formação se dá sob a orientação do Movimento Ruralista ${ }^{2}$, que defendia a proposta de uma instituição para formação específica para professores do meio rural, no âmbito das escolas Normais Rurais.

A primeira escola organizada sob esses moldes foi a Escola Normal Rural de Juazeiro do Norte, implantada em 1934, e assumida pelo poder público somente em 1958. Antes, porém, nos anos de 1940, os cursos normais rurais foram transformados em cursos normais

\footnotetext{
${ }^{2}$ Correspondente ao Ruralismo pedagógico. MARGENS - Revista Interdisciplinar Versão Digital-ISSN: 1982-5374
} 
regionais com base na Lei Orgânica $n^{\circ}$ 8.530/46, sob a influência do Ruralismo Pedagógico ${ }^{3}$ (WERLE; METZLER, 2010). É imperioso ressaltar que a tentativa de uma formação específica não prevaleceu e o que se estabeleceu foi uma formação de caráter generalista sob o julgo de que os professores deveriam ser capacitados para "desenvolver os mesmos saberes e competências do ensino fundamental, independentemente da diversidade de coletivos humanos" (ARROYO, 2012, p. 361c).

De modo geral, a formação docente passa ao longo do século XX por transformações ligadas ao desenvolvimento do capital. Nesse processo, a formação do/a educador/a do campo é submetida ao silêncio. Com as reformas a partir dos anos 1990, a política educacional articulada às determinações dos organismos internacionais, com destaque para o Banco Mundial, produziu mudanças na educação e, por conseguinte, na formação do educador brasileiro. Para Veiga e Viana (2010, p. 16) o eixo norteador dessa mudança é a LDB (n 9.394/96), a qual passa a “exigir um professor que tenha curso superior”. Isto é, um profissional "preparado para trabalhar com uma nova concepção de currículo, de avaliação e de gestão" (VEIGA; VIANA, 2010, p. 16) em vista de formar o aluno competente para atender com qualidade as exigências do mercado de trabalho.

No âmbito dessa lei é reservado à educação do campo, denominada de educação rural no Art. 28, a adaptação de calendário, metodologia e conteúdos. Como se observa, segue a mesma lógica das leis anteriores, isto é, mantém no silenciamento o protagonismo da população do campo. Isso demonstra que a política educacional existente no campo reafirma a relação de submissão entre campo e cidade, em que escola, currículo e o próprio professor são transportados da cidade para o campo.

No caso do professor, a imagem historicamente atribuída é a de que o profissional rural não precisa ser educado, já que a lida dos sujeitos do campo é com a terra, logo, não precisam de muitas letras (ARROYO, 1999a). De certo modo, isso ajuda explicar a existência

\footnotetext{
${ }^{3}$ Movimento que "discutiu, elaborou e divulgou proposições para a educação escolar das populações rurais" (ANTUNES-ROCHA, 2011, p. 130), com o objetivo de arrefecer o esvaziamento populacional das zonas rurais, evitar os problemas sociais nas cidades e fixar o homem no campo. 
de 160.319 professores no campo sem formação superior, dos quais 156.190 com ensino médio e 4.127 com ensino fundamental (BRASIL/INEP, 2011).

No Estado do Pará, os dados do Censo 2007 demonstraram que apenas cerca de 10\% dos docentes que atuam na educação básica possuem formação inicial adequada às suas funções (PARÁ, 2009). Em Portel, lócus desse estudo, dos 459 professores do campo, $381^{4}$ possuem o ensino médio, representando um percentual de mais de $80 \%$ de professores sem formação inicial em nível superior. Esses dados refletem em parte o tratamento atribuído ao campo no decorrer da história, ou seja, campo como lugar do atraso, daquilo que sobra além da cidade, do espaço a ser superado (MUNARIN, 2006; ARROYO, 2004b). E mais, denuncia a qualidade da formação das pessoas que estão trabalhando nas escolas do campo.

Cabe ressaltar que a partir da LDB, várias políticas que incidem sobre a formação de professores foram aprovadas. Nesse particular, destacam-se as Diretrizes Curriculares Nacionais para Formação de Professores da Educação Básica em nível superior, curso de licenciatura e de graduação plena instituída por meio do Parecer $n^{\circ}$ 009/2001, aprovado pelo CNE e na Resolução n¹/2002 que no geral pautam-se em parâmetros urbanos.

Na mesma direção destaca-se o Plano Nacional de Educação (PNE), tanto o anterior $\left(\mathrm{n}^{\circ}\right.$. 10.172/2001) como o atual (PL $\mathrm{n}^{\mathrm{o}}$ 8.035/2010). O primeiro plano, embora se tenha definido "tratamento diferenciado para as escolas do campo" (HENRIQUES, 2007, p. 17), prevaleceu à manutenção do caráter da educação capitalista, tendo em visto comungar com as ações estabelecidas no Fórum Mundial de Educação, realizado em Dakar, em 2000. O atual PNE (PL nº 8.035/2010) segue o modelo de visão sistêmica da educação estabelecida em 2007, com a criação do Plano de Desenvolvimento da Educação, tendo por objetivo a melhoria da qualidade da educação.

Concernente a isso traça na meta 15 que todos os professores da educação básica devem possuir formação específica de nível superior, obtida em curso de licenciatura, na área de conhecimento em que atua. Essa meta envolve um conjunto de estratégias a serem desenvolvidas em parceria entre os entes federados. Considera-se que tal meta representa um

\footnotetext{
${ }^{4}$ Dados disponibilizados pela Secretaria Municipal de Educação - SEMED de Portel em 2011. 
passo importante para a formação do educador brasileiro. No entanto, é uma questão que precisa ser acompanhada para não incorrer outra vez na política da titularização.

A Associação Nacional de Pós-Graduação e Pesquisa em Educação (ANPEd) tem defendido a aprovação do PNE como política de Estado, pois "só como política de Estado que poderá ser assegurada uma educação pública, democrática, laica e de qualidade como direito social para todos e todas e para o futuro do país" (OLIVEIRA, 2010, p. 11). O exposto permite indicar a LDB, o PNE (Lei n 10.172/2001) e as Diretrizes Curriculares Nacionais para a Formação de Professores da Educação Básica, em nível superior, curso de licenciatura, de graduação plena, como as principais políticas educacionais que estão no bojo das reformas educativas e, em que pese resguardar preceitos eurocêntricos, contribui para a criação e organização de uma legislação para o campo, tal como a aprovação das Diretrizes Operacionais para a Educação Básica nas Escolas do Campo (DOEBEC).

É fundamental afirmar que essas políticas educacionais trazem certos avanços significativos à educação brasileira, principalmente, no concernente à realidade da educação do campo e a política de formação docente. Entre esses avanços, registra-se a exigência da formação superior, a organização curricular por área de conhecimento e a possibilidade de criação de um curso de licenciatura com identidade própria, o que abre perspectiva para a garantia das especificidades. Todavia, mantêm-se concepções que ainda defendem a lógica dominante e isso é visível na proposta de formação docente de base generalista defendida nessas leis.

A formação nesses moldes contribui para negligenciar e excluir a realidade do campo. Realidade essa que passa a ganhar outra dimensão no cenário nacional com a aprovação das Diretrizes Operacionais para as Escolas de Educação Básica do Campo (DOEBEC), em 2002, embora estas mantenham o estabelecido pela LDB: resoluções e diretrizes vigentes no país. Tais diretrizes, de certo modo, rompem com a sedimentação imposta e avançam no sentido de valorizar e reconhecer a diversidade cultural e educacional do campo.

A partir desse documento, a formação específica para os docentes do campo defendida pelo Movimento de Educação do campo passou a ser difundida, possibilitando a criação do curso de LPEC/Procampo. Aqui cabe destacar que esse curso inaugura uma nova 
configuração no âmbito da formação docente no campo, cuja organização e metodologia buscam teoricamente voltar-se para a valorização do contexto do campo.

Enfatiza-se, que até então, a formação desse docente se resumia em grande parte ao curso normal em nível médio, com habilitação em magistério e em nível superior no curso de pedagogia, com habilitação para docência nos anos iniciais do ensino fundamental, todos apresentando características urbanocêntrica. Importa salientar que a formação específica não significa retorno à ideia ruralista do início do século XX, nem formar professores na mesma proposição da política das especializações, mas formar o educador comprometido com as matrizes históricas, sociais e culturais do campo.

As DOEBEC trazem elementos que ressignificam a formação do docente do campo. Contudo, são elementos que dependem da materialidade e institucionalização dessa lei na sua dimensão. Essa é uma questão importante de ser refletida frente à política de formação que vem se estabelecendo nos últimos anos com o PDE e "Plano de Metas Compromisso Todos pela Educação", lançados em 2007, com o objetivo de melhorar a educação no país em todas as suas etapas em um prazo de quinze anos, com foco prioritário na educação básica e pautado na elevação dos indicadores educacionais.

Pondera-se que diante da preocupação com o referido quantitativo o MEC propõe a partir desse plano fazer a formação inicial do educador brasileiro, em especial do educador do campo, nos cursos de LPEC apoiados pelo Procampo. Na perspectiva de implantação imediata deste programa, o MEC convocou por meio de carta-convite as universidades públicas que já acumulavam experiência com a formação de educadores do campo para implantar o Projeto Piloto do curso de LPEC. Desse modo, foram convidadas sete $\left(07^{5}\right)$ universidades federais, em que desse total, 04 (UnB, UFMG, UFS e UFBA) começaram a desenvolver o referido curso no mesmo ano.

A partir da experiência desses projetos-pilotos, o MEC lançou em 2008 o edital n02/2008 convocando as IPES a apresentarem projetos de criação da nova licenciatura. Na mesma expectativa este Ministério lançou em 2009 o edital n09/2009. Nesses editais,

\footnotetext{
${ }^{5}$ UnB, UFBA, UFPA, Universidade Federal de Campina Grande - UFCG, UFMG, UFS, Universidade Tecnológica Federal do Paraná (UTFPR). MARGENS - Revista Interdisciplinar Versão Digital-ISSN: 1982-5374 
acentua-se como objetivo do Procampo apoiar e fomentar "projetos de cursos de licenciatura específicos em educação do campo que integrem ensino, pesquisa e extensão e promovam a valorização da educação do campo e o estudo dos temas relevantes concernentes às suas populações" (BRASIL, 2008, p. 01, grifo nosso).

Os editais recomendam ainda que "os projetos apoiados deverão contemplar alternativas de organização escolar e pedagógica" os quais venham contribuir com "a expansão da oferta da educação básica nas comunidades rurais e para a superação das desvantagens educacionais históricas sofridas pelas populações do campo" (BRASIL, 2008, p. 01). Também se exige que os projetos pedagógicos da LPEC contemplem os seguintes critérios:

Os projetos devem prever: a criação de condições teóricas, metodológicas e práticas para que os educadores em formação possam tornar-se agentes efetivos na construção e reflexão do projeto político-pedagógico das escolas do campo; a organização curricular por etapas presenciais, equivalentes a semestres de cursos regulares, em Regime de Alternância entre Tempo-Escola e Tempo-Comunidade, para permitir o acesso e permanência dos estudantes na universidade (tempo-escola) e a relação prática-teoria-prática vivenciada nas comunidades do campo (tempo comunidade); a formação por áreas de conhecimento previstas para a docência multidisciplinar - Linguagens e Códigos, Ciências Humanas e Sociais, Ciências da Natureza e Ciências Agrárias, com definição pela universidade da(s) respectiva(s) área(s) de habilitação; e a consonância com a realidade social e cultural específica das populações do campo a serem beneficiadas, segundo as determinações normativas e legais concernentes à educação nacional e à educação do campo em particular (BRASIL, 2008, p. 02).

Com a emissão desses editais o MEC torna público, em âmbito nacional, à institucionalização do Procampo e inaugura assim uma política específica de formação para os/as educadores/as do campo no intuito de contribuir com a valorização da educação do campo. A partir dos referidos editais várias universidades públicas que tiveram seus projetos aprovados junto ao MEC passaram a ofertar a LPEC. Muitas delas já somavam experiências dos cursos de Pedagogia da Terra, o que contribuiu para a oferta da LPEC em 31 universidades públicas em todo país. No Estado do Pará, a licenciatura em tela começa a ser MARGENS - Revista Interdisciplinar Versão Digital - ISSN: 1982-5374 
implementada em 2009, após aprovação das propostas pedagógicas do Instituto Federal de Educação, Ciência e Tecnologia do Pará (IFPA) e também da Universidade Federal do Pará6, por meio do campus de Abaetetuba. No Marajó, em especial, no município de Portel, lócus desse estudo, o Procampo começou a ser desenvolvido pelo IFPA em 2010.

A oferta desta licenciatura no Marajó é justificada no Projeto Pedagógico do Curso pela carência de "política de formação, capaz de atender a demanda pela formação escolar dos sujeitos do campo" (IFPA, 2011, p. 08), bem como pela insuficiência da política de acesso ao ensino superior para os professores do campo desenvolvido pelo MEC no sentido de atender as exigências da LDB (Ibidem, p. 08).

A oferta desta formação é justificada também, por entender-se que

A formação de professores do campo significa não apenas a garantia de acesso à educação de qualidade pelas crianças, jovens e adultos do campo que historicamente foram excluídos do direito e educação, mas principalmente a possibilidade de intervir nas escolas do campo em que atuam; pela inserção de uma gestão escolar democrática e autônoma, a qual deve se dar pela elaboração coletiva do Projeto político-Pedagógico da escola, no decorrer do tempo-escola/estágio (IFPA, 2011, p. 11).

Para atender a referida justificativa, o curso objetiva: "formar professores para atuar nas séries finais do Ensino Fundamental, no Ensino Médio e na Educação de Jovens e Adultos na área das ciências da Natureza e Matemática, e na área das Ciências Humanas das escolas do campo" (IFPA, 2011, p.14). O curso apresenta uma organização curricular que prevê etapas presenciais e semipresenciais em regime de alternância pedagógica entre Tempo Acadêmico (TA) e Tempo Comunidade (TC).

A aposta é por uma formação que compreenda o processo de humanização como fruto do saber, do ser e do estar no mundo. Isso possibilita comungar do pensamento de Menezes Neto (2009, p. 36) quando afirma que "o fundamental para os cursos de licenciatura do campo

\footnotetext{
${ }^{6}$ Referida licenciatura é ofertada no campus de Marabá (UFPA), desde 2008, por meio do Reuni. 
é que a formação do professor não perca o conceito de totalidade e nem seja dirigida a um conhecimento produtivista".

A aprovação do Procampo e o reconhecimento de uma formação inicial para o docente do campo ajudam a trazer para o cenário educacional questões até então silenciadas. Com o Procampo é possível dizer que a política educacional ganha uma nova estrutura. Isso não significa entender este programa a partir de uma visão ingênua e romântica em que somente os interesses da população do campo será garantido ou que é uma estratégia do Estado para dizer que assegurará o direito dos sujeitos do/no campo, muito embora represente uma das metas do novo Plano Nacional de Educação (2011-2010).

Na opinião dos colaboradores desta investigação o Procampo é uma política voltada para a construção de um outro modelo e/ou paradigma educacional e está contribuindo para mudar a concepção de vida no campo, bem como a mentalidade do que é fazer educação do campo no Brasil e Amazônia. Compreende-se que se trata de uma política pontual e não permanente, mas que representa condição fundamental para a constituição e institucionalização de uma nova política de formação inicial do docente do campo.

\section{Considerações Finais}

Com o estudo apreende-se que a proposta da LPEC tem como desafio conseguir materializar-se em um projeto de formação docente pautado em concepção e princípios epistemológicos capazes de fazer a ruptura com a visão reducionista de currículo, de educação e conhecimento. Uma formação nessa perspectiva requer uma visão humana e emancipadora que compreenda o campo não só como espaço de produção material, mas de vida em que os sujeitos possam proferir a palavra independente de sua raça, religião, etnia, entre outros.

É possível dizer que o Procampo, como principal política que respalda essa formação, embora seja uma política pontual aventa para o reconhecimento das marcas identitárias da população do campo, em específico desta investigação, dos ribeirinhos do Marajó. Enquanto 
política de formação entende-se o Procampo como pressuposto de uma nova concepção de qualificação profissional, voltada para a formação de um educador mais crítico e consciente de seus direitos e deveres, bem como a conquista de novas escolas, que não se restringem a estrutura física, mas são abertas ao diálogo, ao debate, ao conflito, às contradições. Uma escola real capaz de discutir e contribuir com a melhoria do desenvolvimento educacional dos sujeitos do campo.

Diante disso, pode-se afirmar que essa formação em Portel no Marajó representa para a educação do campo possibilidade de reconhecimento da realidade do campo e dos sujeitos como sujeitos de direitos. Trata-se de uma importante ação afirmativa para a educação do campo na Amazônia paraense e marajoara, visto que é uma possibilidade concreta de se construir e efetivar na prática uma educação capaz de romper com a visão urbanocêntrica, que há muito permeia a educação dos povos que habitam a área rural, e consolidar-se em uma verdadeira e autêntica educação do e no campo da Amazônia Paraense.

\section{Referências}

ANTUNES-ROCHA, Maria Isabel. Formação de docentes para atuação nas Escolas do Campo: lições aprendidas com as Escolas Normais Rurais. In: MUNARIM, Antônio; BELTRAME, Sônia; CONTE, Soraya Franzoni; PEIXER, Zilma Isabel (Orgs.). Educação do campo: reflexões e perspectivas. 2. ed. Florianópolis: Insular, 2011.

ARROYO, Miguel González. A educação básica e o movimento social do campo. In: FERNANDES, Bernardo Maçano. A Educação Básica e o Movimento Social do Campo. Brasília, DF: Articulação Nacional Por Uma Educação Básica do Campo, 1999a.

A Educação Básica e o Movimento Social do Campo. In: CALDART, Roseli Salete; MOLINA, Mônica Castagna (Org.). Por uma educação do campo. Petrópolis, RJ: Vozes, 2004b. 
Formação de Educadores do campo. In: CALDART, Roseli Salete et all (Orgs.). Dicionário da Educação do Campo. Rio de Janeiro, São Paulo: Escola Politécnica de Saúde Joaquim Venâncio, Expressão Popular, 2012c.

BRASIL. Secretaria de Educação Continuada, Alfabetização e Diversidade - Secad. Edital $\mathbf{N}^{\mathbf{0}}$ 2, de 23 de Abril de 2008. Chamada Pública para seleção de projetos de Instituições Públicas de Ensino Superior para o Procampo. Disponível em: 〈http://portal.mec.gov.br>. Acesso em 20 de set de 2010a.

INEP. Resultados do Ideb 2011: metas de qualidade foram cumpridas. Brasília, 2012b. Disponível em: 〈http://portalideb.inep.gov.br/>. Acesso em 22 de ago de 2012.

CALDART, Roseli. A escola do Campo em Movimento. In: BEJAMIN, César; Projeto Popular e Escolas do Campo. Brasília, DF: Articulação Nacional por Uma Educação do Campo, 2000a. (Coleção Por Uma Educação do Campo, nº. 03).

Licenciatura em Educação do Campo e projeto formativo: qual o lugar da docência por área? In: MOLINA, Mônica C.; SÁ, Laís M. (Orgs.). Licenciaturas em Educação do Campo: registros e reflexões a partir das experiências piloto. Belo Horizonte: Autêntica Editora, 2011b.

FREIRE, Paulo. Pedagogia da Autonomia: saberes necessários à prática educativa. São Paulo: Paz e Terra, 1996.

GARCIA, Carlos M. A formação de professores: novas perspectivas baseadas na investigação sobre o pensamento do professor. In: NÓVOA, Antônio (Coord.). Os professores e sua formação. Portugal: Publicações Dom Quixote, Lda - Instituto de Inovação Educacional e autores, 1992.

GATTI, Bernadete A; BARRETO, Elba S.de S.; ANDRÉ, Marli E. D. Políticas Docentes no Brasil: um estado da arte. Brasília: UNESCO, 2011.

HENRIQUES, Ricardo et al (Orgs). Educação do Campo: diferenças mudando paradigmas. Brasília, DF: Cadernos Secad/MEC, 2007. 
IFPA. Projeto Pedagógico Licenciatura em Educação do Campo Área de Concentração: ciências da natureza e matemática. Belém: IFPA, 2011 (Não publicado).

NÓVOA, A. Formação de professores e profissão docente. In: Os professores e sua formação. Portugal: Publicações Dom Quixote, Lda - Instituto de Inovação Educacional e autores, 1992.

MENEZES NETO, Antônio Júlio de. Formação de professores para a educação do campo: projetos sociais em disputa. In: ANTUNES-ROCHA, Maria Isabel; MARTINS, Aracy Alves (Orgs.). Educação do Campo: desafios para a formação de professores. Belo Horizonte: Autêntica Editora, 2009.

MUNARIM, Antônio. Elementos para uma política pública de Educação do Campo. In: MOLINA, Mônica Castagna. (Org.). Educação do Campo e Pesquisa: questões para reflexão. Brasília: Ministério do Desenvolvimento Agrário, 2006.

OLIVEIRA, Dalila A. Apresentação. In: DOURADO, Luiz F. (Coord.). Por um plano nacional (2011-2020) como política de Estado. Rio de Janeiro: ANPED, 2010.

PARÁ. SEDUC. Plano de Formação Docente do Estado do Pará. Protocolo SEDUC-IES, 2009. Disponível em: 〈http://www6.seduc.pa.gov.br/planodeformacao/index.php>. Acesso em: 20 de abr de 2011.

PORTEL. SEMED. Dados educacionais. Portel, 2011.

SHEIBE, Leda. Valorização e formação dos professores para a Educação Básica: questões desafiadoras para um novo Plano Nacional de Educação. Revista Educ. Soc., Campinas, v. 31, n. 112, p. 981-1000, jul.-set. 2010. Disponível em: 〈http://www.cedes.unicamp.br>. Acesso em: 20 de janeiro de 2012.

VEIGA, Ilma Passos A. Professor: Tecnólogo do ensino ou agente social. In: Formação de professores: políticas e debates. Campinas, SP: Papirus, 2002. 
; VIANA, Cleide $\mathrm{M}^{\mathrm{a}} \mathrm{Q}$. Q. Formação de professores: um campo de possibilidades inovadoras. In: SILVA, Edileuza F. da (Orgs.). A escola mudou. Que mude a formação de professores. Campinas, SP: Papirus, 2010.

WERLE, Flávia Obino Corrêa; METZLER, Ana Maria Carvalho. Contextos, institucionalização e práticas pedagógicas em Escolas Normais Rurais. In: Educação Rural: práticas civilizatórias e institucionalização da formação de professores. São Leopoldo: Oikos; Brasília: Liber Livro, 2010. 